\title{
Empreendedorismo e inovação: a evolução dos fatores que influenciam o empreendedorismo corporativo
}

\author{
Viviane Brandão Miguez Mestre em Engenharia do Conhecimento. Universidade Federal de Santa Catarina (UFSC) - Brasil. \\ vivianemiguez@gmail.com \\ Álvaro Guillermo Rojas Lezana Doutor em Engenharia Industrial. Universidade Federal de Santa Catarina (UFSC) - Brasil. \\ alvarolezana@ufsc.br
}

\section{RESUMO}

Este artigo tem por objetivo mostrar a evolução de fatores que influenciam o empreendedorismo corporativo por meio da análise de variáveis (e.g. atividade empreendedora, oportunidade percebida e capacidade percebida) que interferem no processo de inovação e no empreendedorismo no Brasil. Para tanto, identificou-se na literatura, os fatores que influenciam o processo de inovação e o empreendedorismo corporativo, descreveu-se a relação entre esses fatores, posteriormente, baseado em dados coletados pelo Global Entrepreneurship Monitor (GEM), definiu-se os fatores que determinam os níveis nacionais de atividade empreendedora, determinou-se variáveis ligadas a inovação, apresentou-se as variáveis no período de 2001 a 2015 e por fim, relacionou-se estas variáveis com os fatores de influência. Os principais resultados demonstram relações de fatores como percepção de oportunidades e capacidades e aspirações de crescimento e inovação, capacidade percebida e liderança. Apresentam ainda, a relação de alguns fatores que influenciam o desenvolvimento de negócio e o processo de inovação no Brasil.

Palavras chave: Empreendedorismo. Inovação. Empreendedorismo Corporativo.

\section{Entrepreneurship and innovation: the evolution of the factors that influence corporate entrepreneurship}

\begin{abstract}
This article aims to show the evolution of factors that influence corporate entrepreneurship through the analysis of variables (eg. entrepreneurial activity, perceived opportunity and perceived capacity) that interfere in the process of innovation and entrepreneurship in Brazil. In order to do so, the factors influencing the innovation process and corporate entrepreneurship were identified in the literature, the relationship between these factors was described. Then, based on data collected by the Global Entrepreneurship Monitor (GEM), the factors which determine the national levels of entrepreneurial activity were defined; variables related to innovation were determined; the variables in the period from 2001 to 2015 were presented; and finally, the variables were related to the influence factors. The main results demonstrate relations between factors such as perception of opportunities and capacities, aspirations of growth and innovation, perceived capacity and leadership. They also present the relation between some factors that influence business development and the innovation process in Brazil.
\end{abstract}

Keywords: Entrepreneurship. Innovation. Corporate entrepreneurship. 


\section{INTRODUÇÃO}

A velocidade de mudança do ambiente em que as organizações estão inseridas aumenta rapidamente, fazendo com que elas necessitem obter novas vantagens competitivas sustentáveis, renovando-se constantemente (MEISSNER; KOTSEMIR, 2016; LEWANDOWSKA; SZYMURA-TYC; GOLEBIOWSKI, 2016). As demandas e mudanças do ambiente exigem adaptação das organizações tanto por meio do Empreendedor, quanto por meio da inovação.

A inovação tem um papel importante nas atividades econômicas, não apenas em países com economias desenvolvidas, mas também em países com economias em desenvolvimento. A inovação é um dos principais motores do crescimento econômico (THE GLOBAL INNOVATION INDEX, 2015), e nesse sentido, alguns países em desenvolvimento têm investido em políticas que aumentem sua capacidade de inovação. Embora sejam diversos os fatores que interferem na capacidade de inovação e nos resultados do crescimento econômico do pais, 0 empreendedor tem um papel significante (GEM, 2016). É ele quem identifica as políticas do país e aproveita-as para alavancar a inovação.

A essência da relação entre o empreendedorismo e a inovação, está na percepção e no aproveitamento das novas oportunidades de negócios, criação de novas formas de uso dos recursos (ROSENBUSCH; BRICKMANN; BAUSCH, 2011). Além disso, empreendedorismo corporativo e inovação têm sido associados ao conceito de orientação empreendedora (TURRÓ; URBANO; PERIS-ORTIZ, 2014). Uma empresa empreendedora é aquela que se envolve em inovação de produto-mercado, corre riscos, apresenta inovações proativas, ganhando vantagem competitiva frente aos concorrentes (HAAR; WHITE, 2013).

Outro fator a considerar é a adoção de atividades inovadoras que representam uma mudança fundamental em comportamentos estratégicos das empresas em resposta a mudanças institucionais (CHEN et al., 2014). Em mercados maduros, uma empresa sem a capacidade de se envolver em alguns níveis de empreendedorismo corporativo irá sofrer perda de competitividade (TEECE, 2016). Assim, como a empresa cresce e evolui, uma transformação empresarial é necessária para alcançar a eficiência, melhorar a produtividade e criar riqueza (TURRÓ; URBANO; PERIS-ORTIZ, 2014).

Diante deste cenário, onde o empreendedor busca por oportunidades de transformar ideias em produtos novos/melhorados (TEECE, 2016); a postura da população de um país em relação à sua atividade empreendedora é relevante para o desenvolvimento econômico (GEM, 2016), os fatores de influência contribuem para 0 surgimento de um novo negócio (TURRÓ; URBANO; PERIS-ORTIZ, 2014); 86\% dos entrevistados no Brasil pela pesquisa GEM, veem na mídia frequentemente histórias sobre novos negócios bem-sucedidos e que estes negócios são impulsionados pela eficiência, e $88 \%$ consideram um novo negócio uma boa opção de carreira; busca-se na literatura identificar e relacionar alguns fatores que influenciam neste processo, uma vez que trabalhos anteriores demonstram a existência destes fatores mas sem relacioná-los. A literatura de inovação apresenta os fatores de influência para o processo de inovação (HÜSIG; KOHN, 2003), e a literatura de empreendedorismo da mesma forma (TURRÓ; URBANO; PERIS-ORTIZ, 2014). A relação destes fatores está representada nos valores da sociedade, na interferência que a mídia exerce sobre as pessoas incentivando ou não uma cultura empreendedora ou inovadora. A capacidade das pessoas de perceberem esta interferência, ou perceberem uma nova oportunidade também pode corroborar com o desenvolvimento de estratégias mais oportunas para uma organização. Explicitar estas relações na literatura, proporciona um avanço nos estudos desta área, melhoria nos processos de inovação, capacitação para empreendedores e líderes de equipes de uma organização. Proporciona também novas oportunidades de estudo como analisar estas relações em outros contextos (eg. outros países em desenvolvimento, comparar os resultados com resultados de países desenvolvidos). Posteriormente, verifica-se a congruência dos dados da Global Entrepreneurship Monitor (GEM) da realidade do Brasil e compara-os ao cenário apresentado na literatura. Assim, espera-se contribuir com a literatura da seguinte forma: mostrar que existe relação entre alguns fatores de influência do processo de inovação e alguns fatores do empreendedorismo corporativo, e ainda fornecer um panorama do conhecimento do empreendedor em relação a esses fatores no Brasil, no período de 2001 a 2015.

Este trabalho está organizado da seguinte forma. A seção a seguir apresenta a base teórica relativa à literatura de Empreendedorismo e a Inovação. Na seção três os procedimentos metodológicos para condução da pesquisa são apresentados. Posteriormente, na seção quatro, são apresentados e discutidos os resultados deste estudo. Finalmente, na seção cinco são apresentadas as principais conclusões e considerações finais do trabalho. 


\section{REFERENCIAL TEÓRICO}

Apresenta-se nesta seção uma base do referencial teórico relativa ao empreendedorismo e a inovação.

\subsection{A Inovação}

A inovação, segundo a OECD (2005) pode ser realizada em relação a produtos (bens e serviços), a processos, em marketing e em métodos organizacionais, caracterizando assim os tipos de inovação do ponto de vista de resultado. É o "processo de várias etapas através do qual as organizações transformam ideias em produtos novos/melhorados, serviços ou processos, a fim de avançar, competir e diferenciar-se com sucesso em seu mercado" (BAREGHEH; ROWLEY; SAMBROOK, 2009, p. 1334).

O processo de inovação não ocorre isoladamente dentro da organização (KOEN et al., 2001). Ele está relacionado com (i) a organização por meio de suas metas, estratégias, estruturas disponíveis, modelos de gestão; (ii) com o mercado, economia do país, do mundo, concorrência, informações disponíveis; e ainda, (iii) com os atores que se relacionam com a organização em questão. Estas relações estão representadas na literatura pelos diversos modelos de inovação (ROBERTS, 1984; CLARK; WHEELWRIGHT, 1993; COOPER, 1993; JONASH; SOMMERLATTE, 2001; CHESBROUGH, 2003; MORRIS, 2008). Os modelos lineares motivados pelo avanço tecnológico, empurrado pela tecnologia ou puxado pela demanda (ROTHWELL, 1994) possuem representações mais simplificadas em relação aos fatores de influência. 0 modelo empurrado pela tecnologia foca na representação da busca por novas tecnologias ou puxado pela demanda que foca na necessidade do mercado e neste modelo, a identificação de oportunidades se faz necessária. O modelo denominado "elo-de-cadeia" de Kline e Rosemberg (1986) é um modelo combinado

no qual a inovação tecnológica é o resultado de relações entre oportunidades de mercado e a base de competências por parte das empresas, sendo composta por diversos subprocessos, como invenção, desenvolvimento e comercialização entre os subprocessos. Neste modelo a empresa está posicionada no centro do processo de inovação tecnológica e a pesquisa é vista como uma fonte de solução dos problemas tecnológico (PACAGNELLA J ÚNIOR; PORTO, 2012, p. 333).

Existem ainda modelos integrados em que a motivação advém do impulso tecnológico unido a demanda de mercado base científica e capacidade da organização (TROTT, 2012). Por fim, existem os modelos caracterizados pela inovação aberta que acontece pela externalização do processo em termos de vínculos com fontes de conhecimento e cooperação (CHESBROUGH, 2003).

Os diversos modelos apresentam alguma influência de fatores externos ao processo de inovação, e foi identificado na literatura quais seriam estes fatores. Existem vários estudos que abordam os fatores de influência do processo de inovação (HÜSIG; KOHN, 2003; PACAGNELLA JÚNIOR; PORTO, 2012; SARQUIS et al., 2015), contudo optou-se por adotar os fatores descritos por Hüsig e Kohn (2003). Optou-se por estes fatores porque: (i) são baseados em estudos empíricos o que garante a validade dos fatores na prática, (ii) são genéricos o suficiente para serem relacionados aos fatores de empreendedorismo e (iii) possuem um nível hierárquico capaz de abarcar os fatores utilizados pelos outros autores. Este estudo apresenta uma análise de trabalhos empíricos que buscam determinar quais são os fatores de influência evidenciados pela literatura. Os autores fizeram um levantamento das atividades do processo de inovação e quais eram os fatores considerados pelos diversos trabalhos e os fatores identificados listados no Quadro 1.

Os fatores de influência no processo de inovação estão relacionados entre si e podem facilitar ou dificultar o processo dentro de uma organização (HADJ IMANOLIS, 2003), dependendo da habilidade dos atores envolvidos no processo. Dificuldade de consolidação do empreendimento (TEECE, 2016), supervalorização do negócio e valorização predominante da área tecnológica (SPITZECK; BOECHAT; LEÃO, 2013) são exemplos de fatores que, normalmente influenciam negativamente o processo de inovação, contudo podem servir de estímulo para o líder iniciar um processo ou a formalização de um processo na organização. Hüsig e Kohn (2003) não consideraram as diferenças dos modelos para sua análise, contudo essa diferença não alteraria a classificação uma vez que os fatores de influência não são diferentes conforme o tipo do modelo. 
Quadro 1 - Fatores de influência para o processo de inovação

\begin{tabular}{|l|l|}
\hline Estratégia & $\begin{array}{l}\text { Considera relação entre estratégia da organização e objetivos } \\
\text { do processo de inovação; estratégias de redução para } \\
\text { incertezase redução de riscos; gestão eficiente da informação } \\
\text { como métricas para atingir resultados. }\end{array}$ \\
\hline Cultura & $\begin{array}{l}\text { Comunicação como core competência, comunicação como } \\
\text { estratégia da organização, criatividade organizacional, cultura } \\
\text { colaborativa, valorização de boas ideias, motivação da equipe, } \\
\text { tempo "livre" para criatividade, recursos suficientes. }\end{array}$ \\
\hline Projeto e processo organizacional & $\begin{array}{l}\text { Envolvimento do consumidor, entrosamento da equipe } \\
\text { incluindo equipe de desenvolvimento e parceiros, uso de base } \\
\text { de dados, mercado como ideia central, falta de processo } \\
\text { definido, uso de ferramentas e métodos. }\end{array}$ \\
\hline Liderança & $\begin{array}{l}\text { Apoio de alta gestão, alocação de recursos, suporte de } \\
\text { responsabilidades, líderes influentes e pessoas } \\
\text { comprometidas. }\end{array}$ \\
\hline Processo & $\begin{array}{l}\text { Problema de definição de processo, reconhecimento de } \\
\text { oportunidade, análise de oportunidade, concepção da ideia, } \\
\text { seleção da ideia, pesquisa e refinamento da ideia, projeto e } \\
\text { evolução do conceito. }\end{array}$ \\
\hline
\end{tabular}

Fonte: adaptado de Hüsig e Kohn (2003)

Neste artigo identifica-se que a liderança é exercida ou representada pelo empreendedor, e o ambiente pela estratégia e a cultura da organização. 0 projeto e processo organizacional são considerados no empreendedorismo coorporativo e o processo no processo de inovação.

\subsection{O Empreendedorismo e a inovação}

Empreendedorismo está associado à inovação, sua essência está na percepção e no aproveitamento das novas oportunidades de negócios, em criar uma nova forma de uso dos recursos nacionais, deslocados de seu emprego tradicional e sujeitos a novas combinações (TEECE, 2016). Empreendedorismo corporativo é definido como a soma de inovação de uma empresa, a criação de nova riqueza a partir de novas combinações de recursos. No entanto, no campo de empreendedorismo corporativo, tem havido pouca atenção à influência do ambiente institucional (TURRÓ; URBANO; PERIS-ORTIZ, 2014) e a adoção de atividades inovadoras representa uma mudança em comportamentos estratégicos das empresas em resposta a mudanças institucionais e proporciona uma transformação empresarial necessária para alcançar a eficiência, melhorar a produtividade e criar riqueza (GOMEZHARO, S.; ARAGÓN-CORREA; CORDÓN-POZO, 2011). Estas atividades inovadoras geralmente são motivadas ou impulsionadas por empreendedores.

O empreendedor é uma pessoa criativa, marcada pela capacidade de estabelecer e atingir objetivos e que mantem alto nível de consciência do ambiente em que vive, usando-a para detectar oportunidades de negócios, tomar decisões moderadamente arriscadas e que objetivam a inovação. Um empreendedor é uma pessoa que imagina, desenvolve e realiza visões (TEECE, 2016). 0 empreendedor não espera pela inovação, ele busca-a de forma sistemática por meio de ações proativas. Nem sempre as inovações são de alto impacto, mas acabam por trazer vantagem competitiva para a organização (DORNELAS, 2004).

0 comportamento do empreendedor é influenciado pelo ambiente institucional preocupado com a forma como as pessoas e organizações protegem as suas posições e legitimidade, em conformidade com as regras e normas do ambiente institucional (TEECE, 2016). As instituições consistem em estruturas e atividades cognitivas, normativas e regulatórias. Esses padrões institucionais influenciam fortemente o comportamento organizacional, a inovação e o empreendedorismo. (TURRÓ; URBANO; PERIS-ORTIZ, 2014).

Publicações anteriores como a de Zahra, (1993), Hornsby, et al. (1993) e Gomez-Haro, Aragón-Correa e Cordón-Pozo, (2011), tentaram identificar quais seriam os fatores ambientais e organizacionais que influenciariam o empreendedorismo corporativo. Contudo o estudo de Turró, Urbano e Peris-ortiz (2014), o fizeram baseados em um quadro conceitual que analisa esses fatores ambientais no contexto da inovação utilizando um cruzamento de dados de pesquisas reconhecidas mundialmente, GEM e Doing Business que fornecem medidas objetivas de 
regulamentação de negócios e de sua aplicação em 183 economias destacando os resultados de fatores ambientais sobre a inovação especificamente para o empreendedorismo corporativo. Os autores anteriormente citados, consideraram em sua pesquisa algumas variáveis do empreendedorismo como relevantes e altamente correlacionadas, classificando-as em fatores formais e informais, conforme demonstrado no Quadro 2.

Quadro 2: Fatores de influência do empreendedorismo corporativo.

\begin{tabular}{|l|c|c|}
\hline \multicolumn{1}{|c|}{ Fatores formais } & Procedimentos & Crédito \\
\hline Hipótese confirmada & $\begin{array}{c}\text { Quanto mais procedimentos são } \\
\text { necessários para criar uma } \\
\text { empresa, menor a probabilidade } \\
\text { de empreender }\end{array}$ & $\begin{array}{c}\text { Quanto maior acesso a } \\
\text { financiamentos, maior a } \\
\text { probabilidade de empreender. }\end{array}$ \\
\hline Fatores informais & Cultura empreendedora & Impacto na mídia \\
\hline Hipótese confirmada & $\begin{array}{c}\text { É mais provável que as pessoas } \\
\text { tornem-se empreendedores } \\
\text { corporativos quando estão } \\
\text { envolvidos em uma cultura } \\
\text { empreendedora }\end{array}$ & $\begin{array}{c}\text { É mais provável que as pessoas } \\
\text { tornem-se empreendedores } \\
\text { corporativos quando a mídia } \\
\text { relata frequentemente histórias } \\
\text { sobre novas empresas de } \\
\text { sucesso. }\end{array}$ \\
\hline
\end{tabular}

Fonte: adaptado de Turró, Urbano e Peris-ortiz (2014)

Estes fatores estão ligados à gestão da organização em uma visão de empreendedorismo corporativo. 0 objetivo de analisar e comparar o papel do ambiente para o empreendedorismo corporativo inclui o efeito de fatores informais e formais para empreendedorismo corporativo e o efeito moderador da cultura e da mídia para o empreendedorismo corporativo. A "cultura empresarial" das instituições informais e " impacto mediático " desempenhou um papel significativo na ordem de $99,9 \%$ com o sinal esperado (TURRÓ; URBANO; PERIS-ORTIZ, 2014). Assim, a probabilidade de comportamento empreendedor coorporativo aumenta em contextos em que 0 empreendedorismo é valorizado, ou onde a mídia frequentemente relata histórias de empresas de sucesso, aumenta a probabilidade de comportamento empreendedor corporativo.

\section{MÉTODOS DE PESQUISA}

Esse trabalho visa demonstrar a relação entre o processo de inovação e o empreendedor sob o ponto de vista do empreendedorismo corporativo. Para tanto buscou-se na literatura fatores que influenciam o processo de inovação e fatores que influenciam o empreendedorismo corporativo. Confrontou-se esses fatores com algumas variáveis da pesquisa GEM (Global Entrepreneurship Monitor) para estabelecer uma relação no cenário brasileiro no período de 2001 a 2015 sob o ponto de vista do ambiente e da cultura crescente da inovação. A Figura 1 mostra as etapas dos procedimentos adotados, descritos a seguir. 
Figura 1 - Etapas do procedimento metodológico adotado

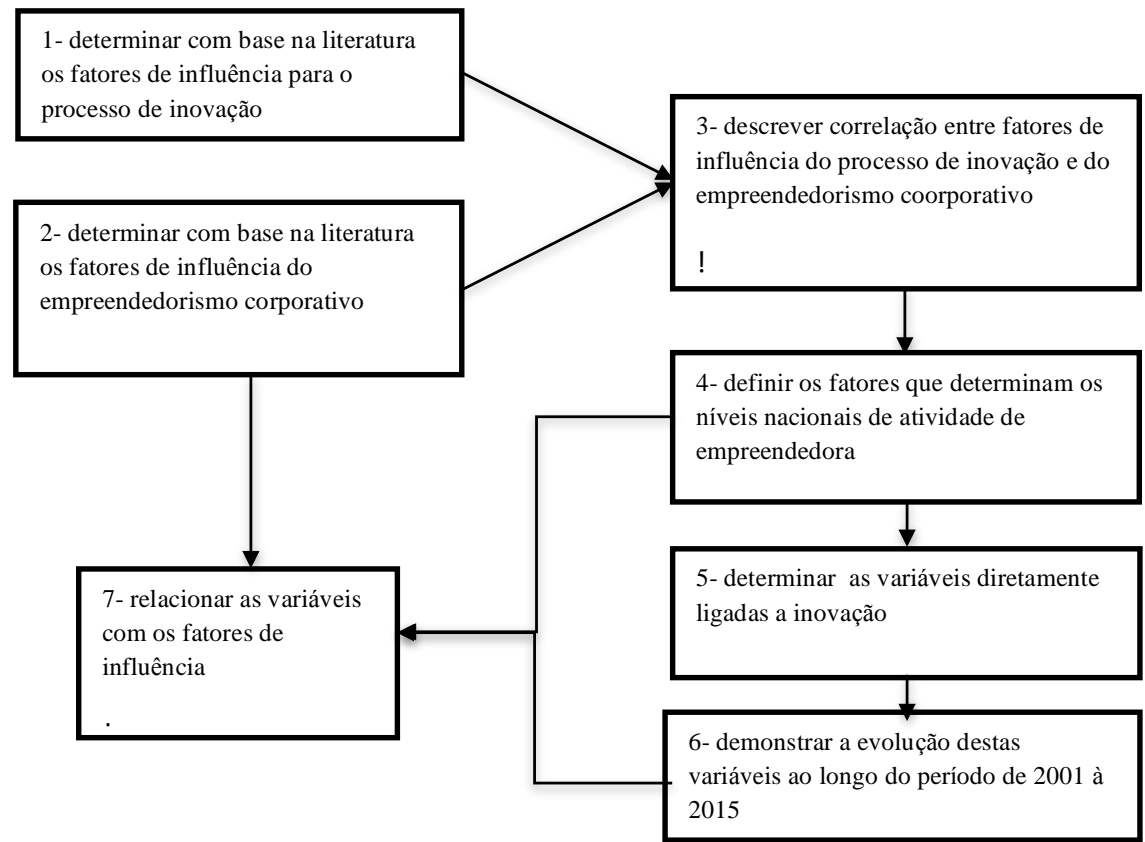

Fonte: elaborado pelos autores

A pesquisa GEM considera ainda a interdependência entre o empreendedorismo e o desenvolvimento econômico a fim de descobrir fatores que incentivam ou dificultam a atividade empresarial, relacionando: valores sociais, atributos pessoais, atributos do ecossistema empreendedor; fornecer uma plataforma para avaliar a atividade empresarial e o crescimento econômico (fatores orientados à eficiência e inovação); e reforçar a capacidade empresarial de uma economia buscando características empreendedoras (GEM, 2016). A Figura 2 apresenta o modelo GEM que já explicita algumas relações entre inovação e empreendedorismo.

\section{Figura 2 - Modelo GEM}

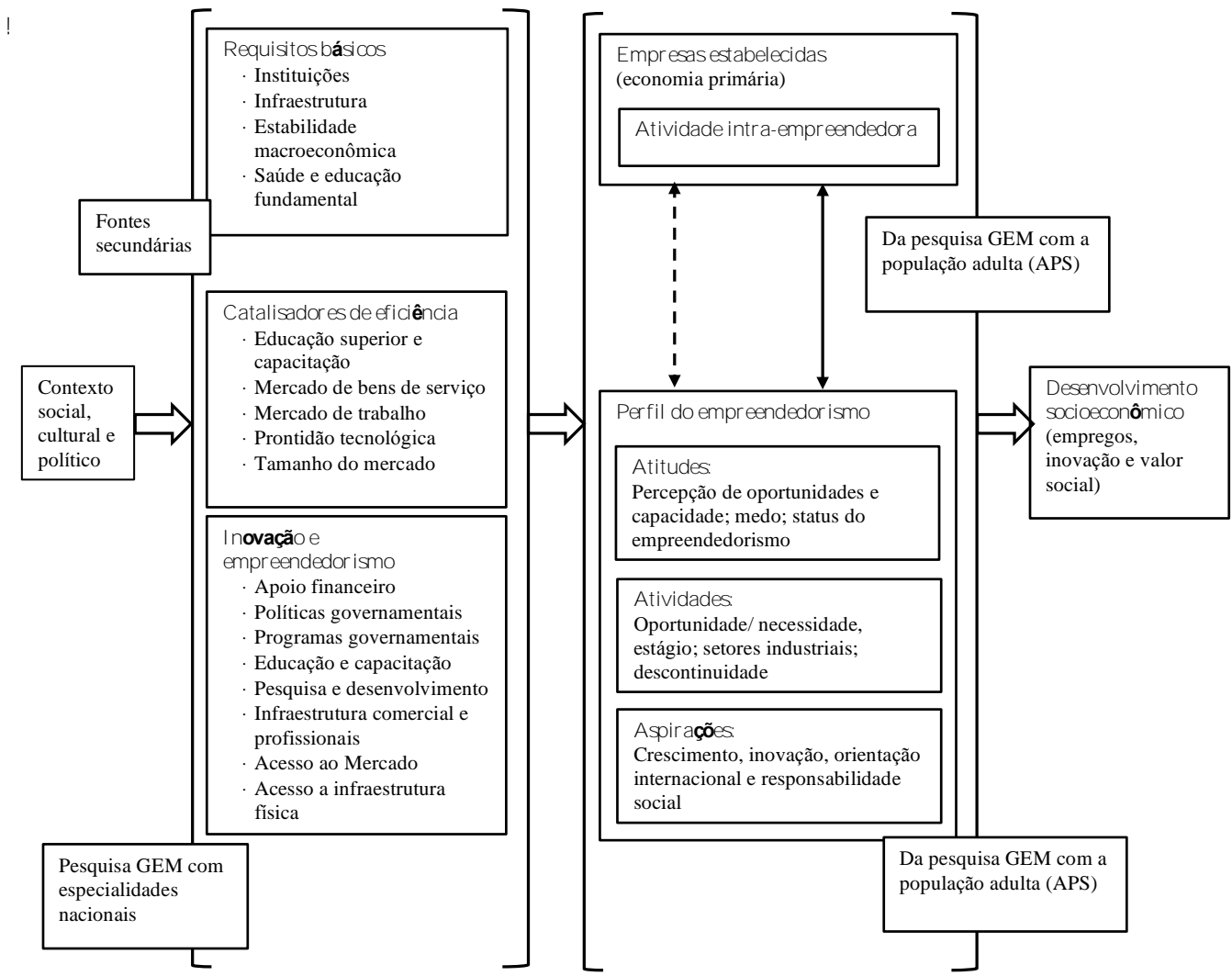

Fonte: GEM, 2013 
Na etapa 6 analisa-se os dados do Brasil e busca-se descrever a evolução do cenário do empreendedor em relação ao ambiente e a cultura com a crescente da inovação usando as variáveis escolhidas na etapa 5 : atividade empresarial; oportunidades percebidas, atividade empreendedora como oportunidade de melhoria, capacidades percebidas pelo empreendedor e atividade empresarial de um novo produto. E, por fim, na etapa 7 relaciona-se essas variáveis com os fatores de influência do processo de inovação e do empreendedorismo, apontando como contribuição, um panorama do conhecimento que o empreendedor possui em relação aos fatores de influência tanto do empreendedor como do processo de inovação para o empreendedorismo corporativo; a liderança caracterizada pelo empreendedor, e o ambiente pela estratégia e pela cultura da organização.

\section{RESULTADOS E DISCUSSÃO}

Nesta seção apresenta-se a relação entre os fatores de influência para inovação e empreendedorismo corporativo e os níveis nacionais de atividade empreendedora determinados pelo GEM; e analisa-se as variáveis relacionadas do GEM e sua evolução no período de 2001 a 2015. Os dados da pesquisa GEM relacionados as variáveis analisadas estão no anexo $\mathrm{C}$ em forma de tabela.

\subsection{Correlação entre os fatores de influência}

Conforme discutido anteriormente, adotou-se neste trabalho como fatores de influência para o processo de inovação os fatores determinados por Hüsig e Kohn (2003): estratégia, cultura, projeto e processo organizacional; liderança e por fim, processo; e como fatores de influência para o empreendedorismo corporativo: procedimentos, crédito, cultura e impacto na mídia determinados por Turró, Urbano e Peris-ortiz (2014). Estes fatores estão interligados da mesma forma que o empreendedorismo está relacionado à inovação, ou seja, uma organização deve empreender para inovar. Turró, Urbano e Peris-ortiz (2014) afirmam que procedimentos demasiados dificultam a atividade de empreender. Para inovar, processos mal definidos podem dificultar a execução de alguma atividade ou a percepção de uma oportunidade ou concepção de uma boa ideia, assim ambos podem influenciar negativamente ou positivamente as atividades de empreender e inovar.

A cultura de ambos os processos deve ser propícia para o contexto e a figura do líder da organização tem um papel determinante. Alguns estudos sobre a cultura e o empreendedorismo afirmam que a cultura se manifesta de várias formas e os valores culturais se manifestam em níveis individuais ou sociais (HOFSTEDE, 2001; BRUTON; AHLSTROM; LI, 2010). Assim, ao nível individual pode-se relacionar aos valores do empreendedor e ao nível de sociedade aos valores do empreendedorismo. Turró, Urbano e Peris-ortiz (2014) afirmam que países em que o empreendedorismo tem alto nível de statusou em que os meios de comunicação relatam frequentemente histórias de empresas de sucesso aumenta a probabilidade de comportamento empreendedorismo corporativo. Este argumento corrobora a relação entre a cultura empreendedora e a inovação, embora criar um novo negócio não seja sinônimo de inovação, uma organização precisa inovar para se manter competitiva (KOEN et al., 2001), sendo assim, um novo negócio precisa inovar para se manter no mercado com sucesso.

O líder deve ser capaz de perceber uma oportunidade, ser criativo o bastante para enfrentar os problemas da organização, deve ser empreendedor, comprometido o suficiente para envolver sua equipe. 0 que corrobora com o estudo de Chen et al., (2014) que investiga os processos pelos quais a liderança influencia o desempenho da inovação de produto e os efeitos do empreendedorismo corporativo neste processo e conclui que o líder de alto escalão é responsável por tomar decisões estratégicas e é responsável pelo desenvolvimento de atividades comerciais ou desenvolvimento de novos produtos.

A fim de relacionar estes fatores de influência pré-determinados e apontar algumas variáveis do GEM as quais poderiam representar esta relação, estudou-se a influência que o contexto social, cultural e político exerce sobre o empreendedorismo e a inovação que por sua vez, está relacionado ao perfil do empreendedor e interfere no desenvolvimento socioeconômico apresentados pela pesquisa GEM.

Algumas relações entre empreendedorismo e inovação caracterizadas pelo quadro inovação e empreendedorismo da figura 2 que descreve algumas variáveis como apoio financeiro, políticas governamentais, programas governamentais, educação e capacitação, pesquisa e desenvolvimento, infraestrutura comercial e profissional, acesso ao mercado, acesso a infraestrutura física e normas culturais e sociais; no quadro perfil do 
empreendedorismo que demonstram algumas características importantes para inovar (percepção de oportunidades e capacidades e aspirações de crescimento e inovação) e no resultado desenvolvimento econômico que é gerado pela geração de empregos, inovação e valor social.

Outra relação claramente representada está baseada nos valores sociais que incluem valores de como a sociedade considera a carreira de empreendedor e como a mídia interfere neste aspecto, esta interferência, corrobora com a cultura da inovação e a estratégia da organização. Outra relação percebida advém dos atributos pessoais baseados na autopercepção, a capacidade de perceber características pessoais dos atores com que se relaciona, para poder aproveitar essas características positivamente é a mesma capacidade de perceber uma oportunidade de inovação, um líder de equipe, ou a criatividade de um colega. Os atributos do ecossistema estão representados pelas relações que o ambiente tem com a organização, fornecedores, mercado, políticas governamentais e a capacidade de perceber estes atributos é a mesma de perceber negócios, oportunidades ou uma necessidade de um cliente/mercado para gerar uma inovação.

Explicitada a correlação entre os fatores de influência do processo de inovação e do empreendedorismo corporativo baseado na pesquisa GEM fez-se uma análise para determinar quais seriam as variáveis usadas para mostrar a evolução deste período (2001 a 2015).

\subsection{Variáveis da pesquisa GEM}

As variáveis apresentadas a seguir serão analisadas sob o ponto de vista da correlação entre empreendedorismo e inovação no Brasil.

\subsubsection{Atividade empreendedora no Brasil}

A atividade empreendedora é uma variável que representa o nível de empreendedorismo do país e situa - Brasil em relação aos outros países participantes da pesquisa. Partindo do pressuposto que 0 empreendedorismo é uma característica importante para inovar, fica clara a necessidade de demonstrar como a taxa da atividade empreendedora evoluiu neste período de 2001 a 2015.

A atividade empreendedora do Brasil está representada na pesquisa GEM da seguinte forma:

- TTE - taxa total de empreendedorismo: TEA + TEE;

- TEA - taxa de empreendedores iniciais: empreendedores nascentes (empreendedores envolvidos na abertura do próprio negócio) e novos (envolvido com um negócio próprio de até 42 meses);

- TEE - taxa de empreendedores estabelecidos: empreendedores envolvidos com um negócio próprio por mais de 42 meses.

A figura 3 mostra a posição do Brasil em relação aos outros países participantes da pesquisa. Em 20010 Brasil ocupa a quinta posição como país mais empreendedor do mundo (nota-se que eram 29 os países ${ }^{2}$ participantes da pesquisa) com atividade empreendedora de $14,2 \%$ que significa que 14 em cada 100 adultos participavam de alguma iniciativa empreendedora (GEM, 2001), este período o país se apresentava em desaceleração de suas atividades econômicas sob o ponto de vista da conjuntura econômica devido à crise energética, à desaceleração da economia americana e à elevação das taxas de juros. Em 2015, este número subiu para 20,98\% e o número de países pesquisados para 60, com estes números o Brasil passou a ser o décimo segundo colocado em atividades empreendedoras. Analisando estes números e comparando-os com os dados coletados ano a ano conforme figura 3, pode-se inferir que embora tenha decaído a posição do Brasil em relação aos outros países, as taxas de empreendedorismo no Brasil mantiveram crescente e com pouca variação de um ano para outro ao longo do período analisado (maior variação ao longo de todo o perío do 9,66\%). Atribui-se então essa variação na posição (de quinto para décimo segundo) a inserção de novos países à pesquisa. Dentre os países participantes da pesquisa GEM, os considerados mais desenvolvidos ${ }^{3}$ obtiveram taxas de empreendedorismo mais baixas do que os países com desenvolvimento relativamente menor (GEM, 2008) e os países com desenvolvimento relativamente menores representam $80 \%$ dos empreendedores da pesquisa. 0 Brasil possui

\footnotetext{
2 Países participantes listados no anexo A

${ }^{3}$ A classificação econômica dos países é a utilizada na própria pesquisa GEM e foi adaptada da composição de macrorregiões geográficas do mundo usada pelas Nações Unidas, disponível no anexo B.
} 
uma TEA maior do que a média $(13,22 \%)$ da pesquisa GEM (2016) e isto significa que sua capacidade empreendedora é alta. A alta capacidade empreendedora é uma característica desejada para o processo de inovação. Pode ser uma característica do líder ou de toda equipe. Deve fazer parte da cultura e da estratégia da organização. Desta forma a capacidade empreendedora é uma variável que será analisada posteriormente porque está fortemente relacionada aos fatores de influência do processo de inovação e do empreendedorismo corporativo.

Figura 3 - Posição do TTE do Brasil em relação aos outros países pesquisados.

\section{Posição da TTE em relação aos outros países participantes da pesquisa}

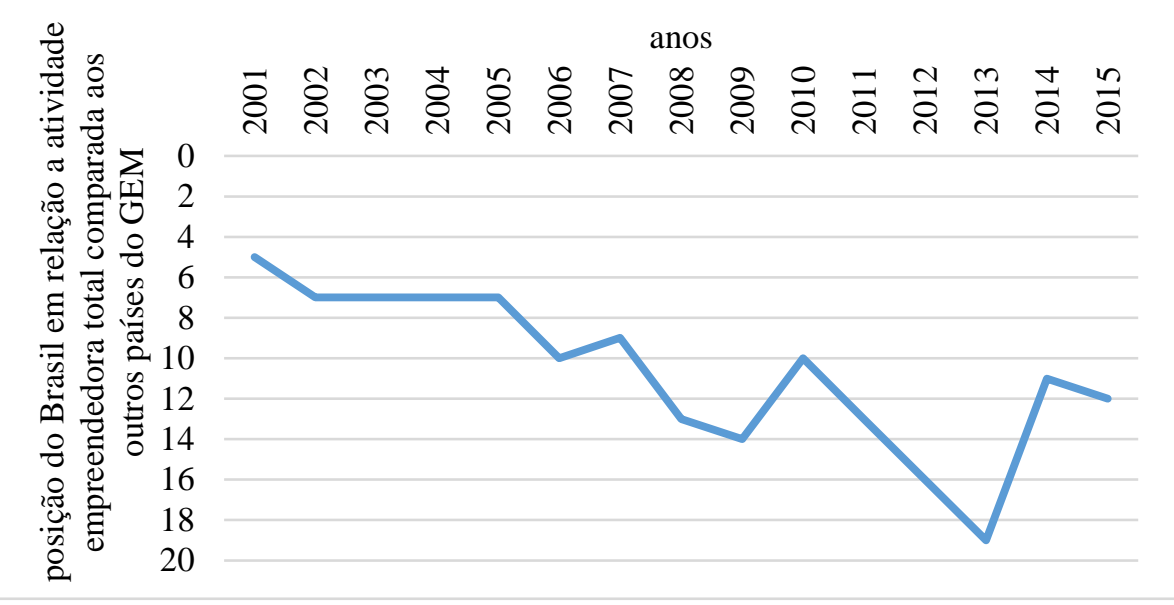

Fonte: elaborado pelos autores com base nos dados da pesquisa GEM (2016).

Ainda sobre a taxa de empreendedorismo do Brasil, pode observar na figura 4 que a taxa de empreendedorismo inicial cresceu de 14\% em 2001 para 21\% em 2015 (total de 7\%) e a taxa de empreendedores estabelecidos cresce de ordem de $8 \%$ para $19 \%$ (total de $11 \%$ ) no mesmo período. 0 fato da taxa de atividade empreendedora entre os empreendedores estabelecidos ter crescido mais do que a taxa dos empreendedores iniciais representa um crescimento na econo mia do país, pois os empreendedores estão conseguindo manter seus negócios em funcionamento por um período maior do que 42 meses. Somente com estes dados, não se pode afirmar que a inovação é responsável por este crescimento, mas pode-se observar posteriormente se há alguma relação com as variáveis: oportunidades percebidas, atividade empreendedora como oportunidade de melhoria, capacidades percebidas pelo empreendedor e atividade empresarial de um novo produto. 
Figura 4 - Atividade empreendedora do Brasil

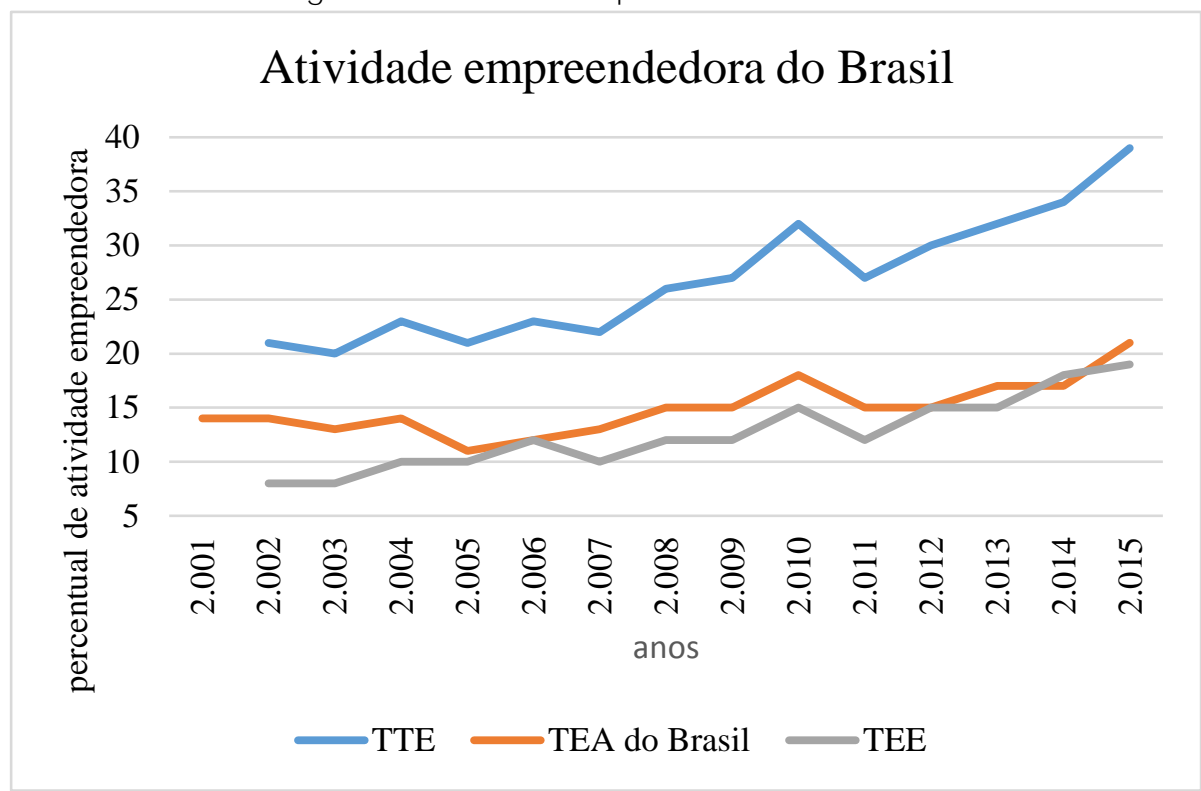

Fonte: elaborado pelos autores com base nos dados da pesquisa GEM (2016)

\subsubsection{Oportunidades percebidas e atividade empreendedora como oportunidade de melhoria}

Estas variáveis representam o potencial inovativo dos empreendedores. A importância destas duas variáveis se dá pela necessidade do empreendedor de perceber as oportunidades de negócio para que seu negócio prospere. Apresenta-se na figura 5 um gráfico mostrando a evolução do cenário brasileiro. No eixo horizontal, representados pelos números de 1 a 15 estão os anos de 2001 a 2015 e no eixo vertical a percentagem de pessoas de idade entre 18 e 64 anos que responderam afirmativamente em relação a variável. Percebe-se que as duas curvas são muito próximas uma da outra, isso mostra uma coerência na resposta dos entrevistados, os que percebem um negócio provavelmente também percebem oportunidades de melhorias. 0 gráfico também representa uma evolução ao longo destes quinze anos que também é coerente com a literatura que afirma que a preocupação com a inovação cresceu nesta década (KURKKIO; FRISHAMMAR; LICHTENTHALER, 2011).

É importante observar o decréscimo ocorrido no último ano, este não foi suficiente para diminuir a taxa de empreendedorismo total do Brasil e também é contraditório ao aumento da capacidade percebida pelo empreendedor representada na figura 6. 
Figura 5 - Potencial Inovativo

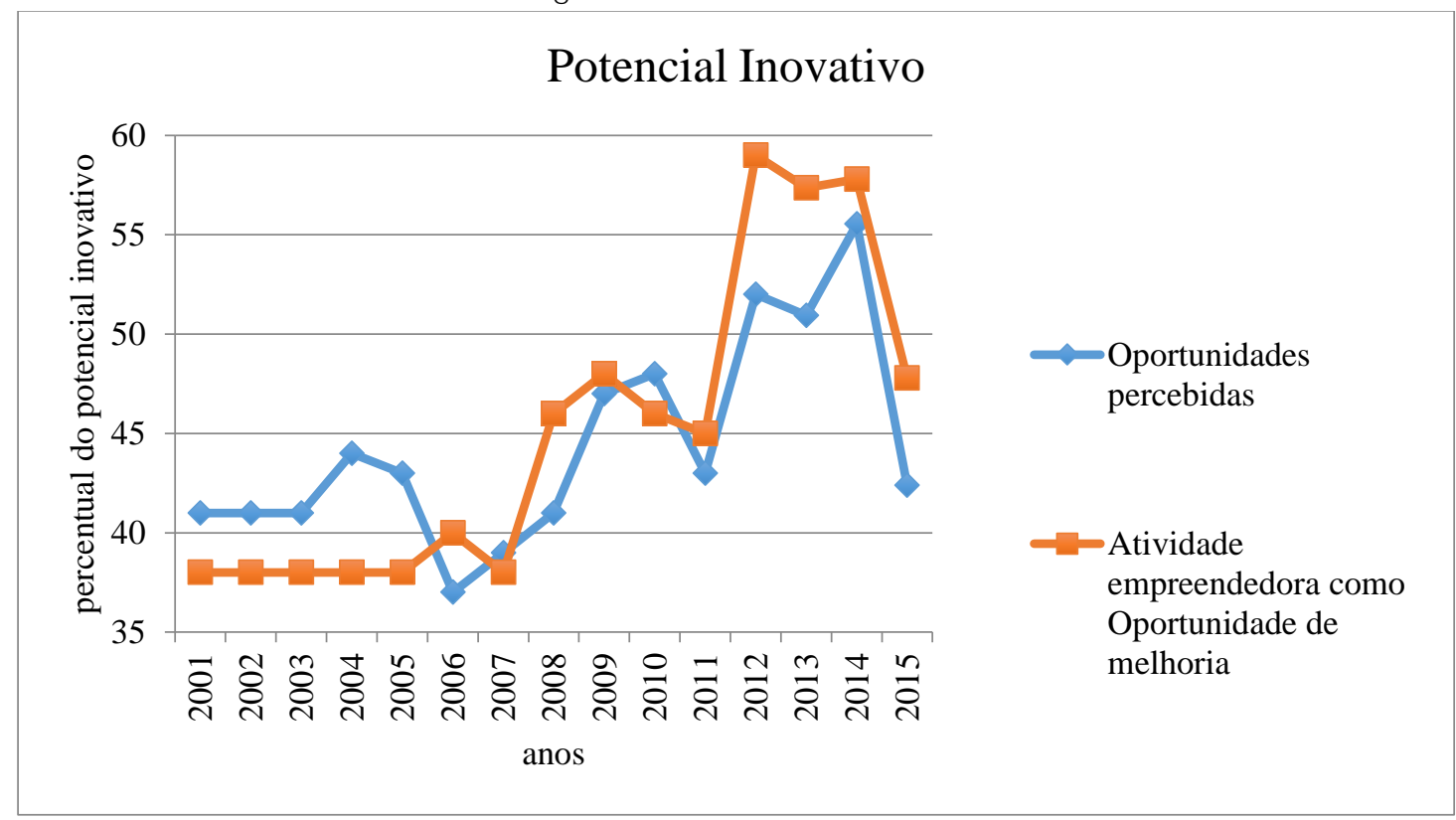

Fonte: elaborado pelos autores com base nos dados da pesquisa GEM (2016).

\subsubsection{Capacidades percebidas pelo empreendedor}

A capacidade percebida pelo empreendedor, representada pelo gráfico da figura 6, representa um líder ou um gestor consciente de suas competências, habilidades e limitações para liderar a organização e sua equipe. No eixo horizontal, representados pelos números de 1 a 15 estão os anos de 2001 a 2015 e no eixo vertical a percentagem de pessoas de idade entre 18 e 64 anos que responderam afirmativamente em relação a variável.

O gráfico também representa ao longo destes doze anos uma variação muito pequena na percepção dos empreendedores de suas próprias capacidades. Atribui-se a este resultado o fato desta característica ser mais difundida entre o senso comum apesar de intrínseca ao perfil do empreendedor.

Diante da afirmação de Hüsig e Kohn (2003) de que a liderança é um fator de influência para inovação e a mesma representa o apoio de alta gestão, alocação de recursos, suporte de responsabilidades, líderes influentes e pessoas comprometidas, e de Turró, Urbano e Peris-ortiz (2014) que afirmam que é mais provável que as pessoas se tornem empreendedores corporativos quando estão em uma cultura emp reendedora ou quando a mídia relata frequentemente casos de novas empresas de sucesso, percebe-se a relação direta do empreendedor como líder de uma organização e este é influenciado constantemente pelo ambiente o qual está inserido. 
Figura 6 - Capacidade percebida pelo empreendedor

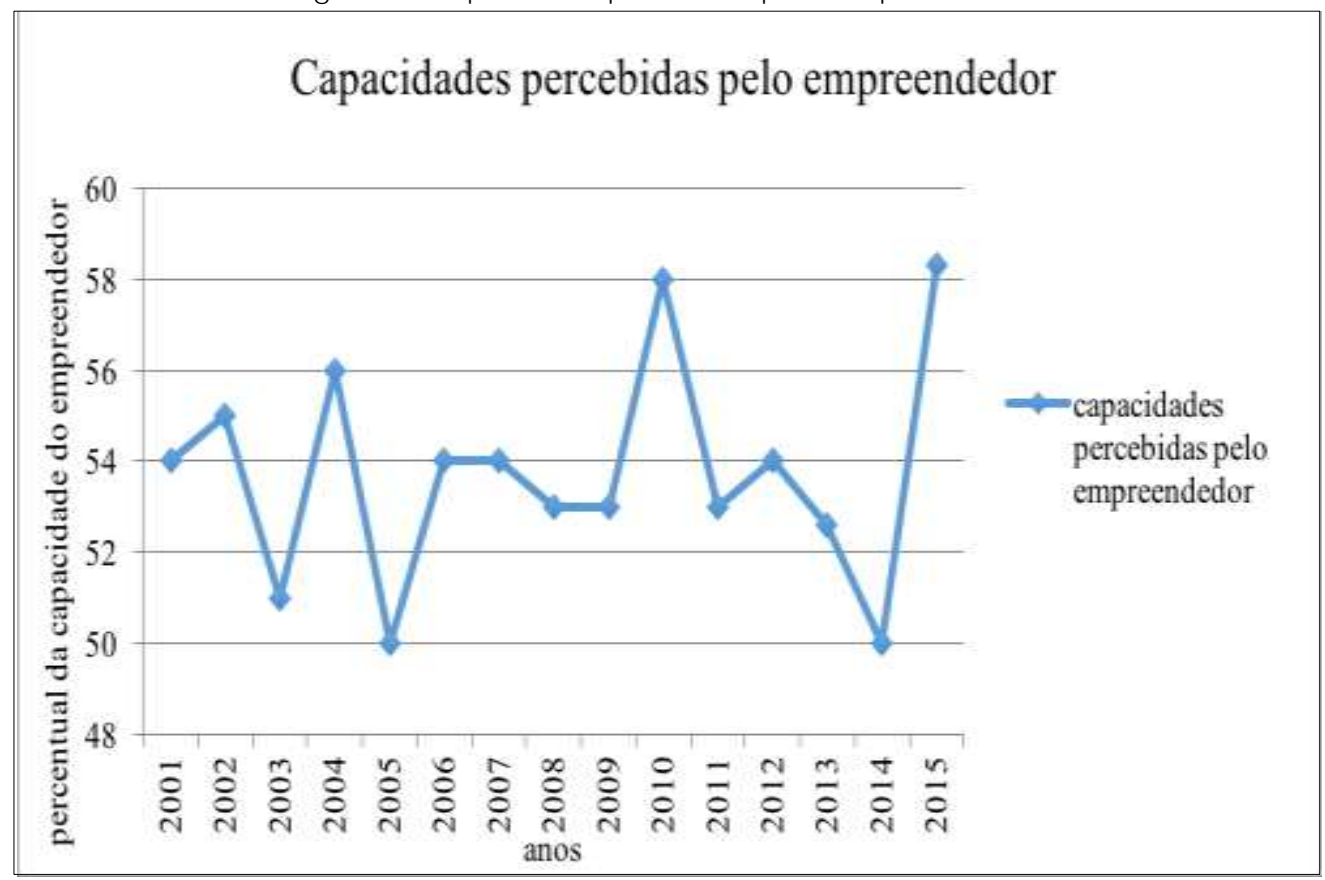

Fonte: elaborado pelos autores com base nos dados da pesquisa GEM (2016).

\subsubsection{Atividade empresarial de um novo produto}

O empreendedor precisa ser capaz de analisar o mercado, o ambiente o qual está inserido, confrontar com as estratégias da organização e reconhecer se um novo produto trará o retorno desejado. 0 gráfico da figura 7 representa o quanto os empreendedores consideram seu produto novo no mercado. No eixo horizontal, representados pelos números de 1 a 15 estão os anos de 2001 a 2015 e no eixo vertical a percentagem de pessoas de idade entre 18 e 64 anos que responderam afirmativamente em relação a variável.

0 gráfico representa ao longo de quinze anos uma decrescente e isto significa que os empreendedores brasileiros não estão considerando seus negócios como inovadores o que é bastante contraditório em uma década onde se fala bastante em inovação, contudo de 2012 a 2015 os empreendedores passaram a enxergar seus produtos como novos no mercado, e pode atribuir esta mudança a difusão dos conceitos e processos envolvidos com inovação.

Figura 7 - Atividade empresarial de um novo produto

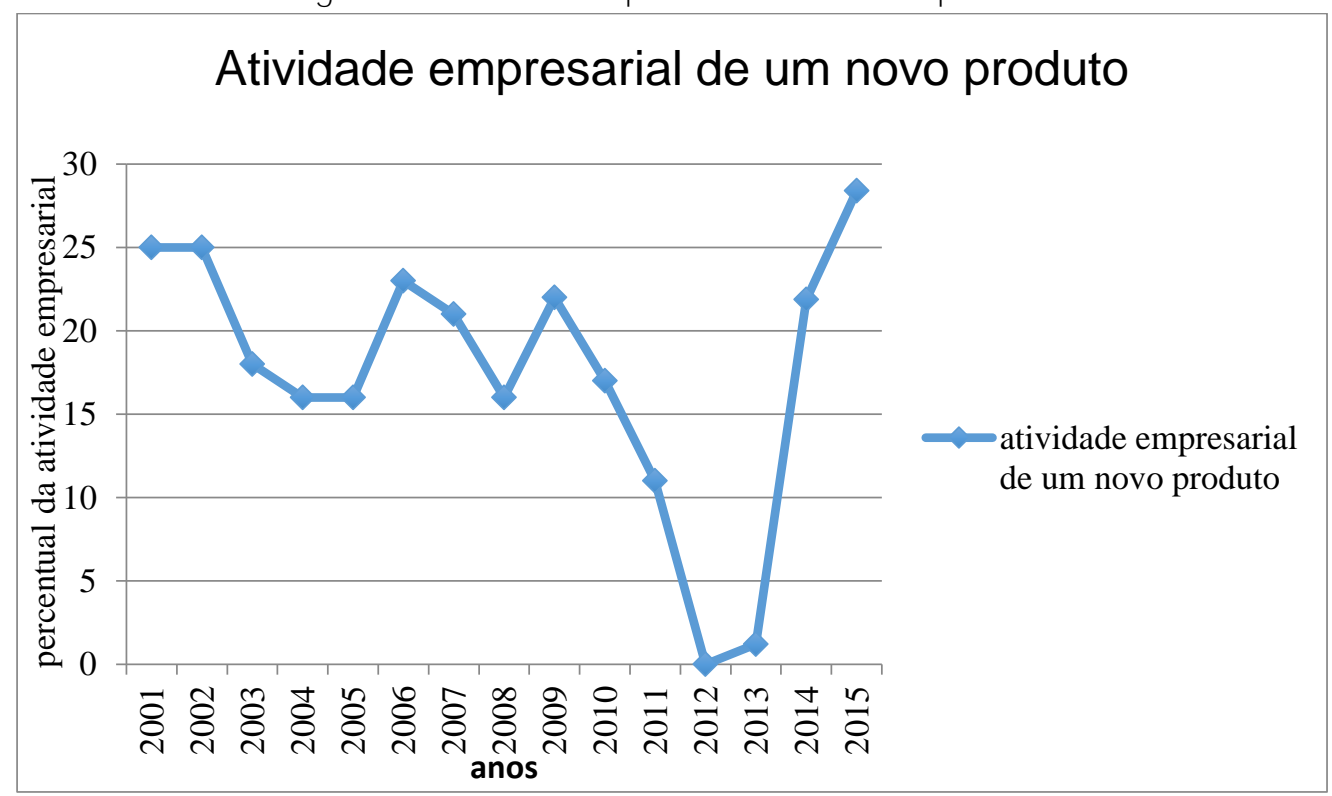

Fonte: elaborado pelos autores com base nos dados da pesquisa GEM 
Todas essas variáveis apresentadas estão interligadas e influenciam uma a outra. As variáveis capacidade percebida, oportunidade percebida, corroboram com o desenvolvimento da atividade empresarial percebida e a atividade de oportunidade de melhoria contribui para o desenvolvimento de novos produtos. Estas duas últimas contribuem para o desenvolvimento da inovação na organização. Os gráficos mostram que o país cresce em relação ao seu potencial de inovar e tem cada vez mais consciência desta condição.

\section{CONCLUSÕES}

Este trabalho, por meio de uma análise de dados secundários coletados por um órgão de excelência em pesquisas (GEM), procurou relacionar fatores que influenciam o desenvolvimento de um negócio, considerando o empreendedor e o processo de inovação observando o cenário brasileiro nos últimos quinze anos. Por meio da pesquisa verificou-se que os fatores levantados na literatura (processo, liderança, cultura da organização, projeto e processo organizacional) e os fatores (procedimentos, crédito, cultura empreendedora e impacto na mídia) influenciaram as variáveis analisadas (atividade empreendedora, oportunidades percebidas, atividade empreendedora como oportunidade de melhoria, capacidades percebidas pelo empreendedor e atividade empresarial de um novo produto). Sendo assim, os fatores ambientais têm relevância para o empreendedorismo corporativo.

0 estudo traz como contribuição um panorama do conhecimento que o empreendedor possui em relação aos fatores de influência tanto do empreendedor como do processo de inovação para 0 empreendedorismo corporativo. Conclui-se que a atividade empreendedora cresceu, em função do aumento das habilidades de perceber e agir em relação aos fatores que influenciam a inovação e o empreendedorismo coorporativo e esta afirmação fica clara quando a atividade empreendedora por oportunidade cresce (37,8 para $47,79)$ e a atividade empreendedora por necessidade decresce $(47,11$ para 42,87$)$. A liderança exercida pelo empreendedor influencia positivamente a tomada de decisão, o desenvolvimento de estratégias e a capacidade de inovar. A cultura representa valores individuais e sociais esses valores são influenciados pela cultura do país e representam o ambiente o qual as organizações estão inseridas. É possível concluir também que o Brasil melhorou sua capacidade de inovar à medida que aumentou sua capacidade de perceber oportunidades e de desenvolver novos produtos.

Esta pesquisa tem algumas limitações que podem ser consideradas em estudos futuros: algumas variáveis disponíveis no GEM foram desconsideradas no processo de análise porque o GEM possui uma grande quantidade de dados e algumas não tinham relação direta com o objeto de estudo e analisar uma grande quantidade de variáveis não permitiria o entendimento de nenhuma dela; 0 nível de análise das variáveis foi genérico, algumas variáveis tinham dados subdivididos o que dificultaria o processo de relacionar com os fatores de influência disponíveis na literatura. Finalmente, análises mais detal hadas podem contribuir para enriquecer os resultados possibilitando uma análise mais completa do cenário brasileiro. 


\section{REFERÊNCIAS}

BAREGHEH, A.; ROWLEY, J.; SAMBROOK, S. Towards a multidisciplinary definition of innovation. Management Decision, v. 47, n. 8, p. 1323-1339, 2009.

BRUTON, G. D.; AHLSTROM, D.; LI, H. L. Institutional theory and entrepreneurship: where are we now and where do we need to move in the future? Enterpreneurship Theory and Practice, v. 34, n. 3, p. 421-440, 2010.

CHEN, Y.; TANG, G.; JIM , .; XIE, Q.; LI, J . CEOs' Transformational Leadership and Product Innovation Performance: The Roles of Corporate Entrepreneurship and Technology Orientation. Journal of Product Innovation Management, v. 31, n. S1, p. 2-17, 2014.

CHESBROUGH, H. Open Innovation: the new imperative for creating and profiting from technology. Cambridge, MA: Harvard Business School Press, 2003.

CLARK, K. B.; WHEELWRIGHT, S. C. Managing new product and process development: text and cases. New York: The Free Press, 1993.

COOPER, R. G. Winning at new products: accelerating the process from idea to launch. Reading (MA): AddisonWesley, 1993.

DORNELAS, J osé Carlos Assis. Empreendedorismocorporativo: Conceitos e aplicações. REVISTA DE NEGÓCIOS, v. 9, n. 2, 2004.

GEM - Global Entrepreneurship Monitor. Empreendedorismo no Brasil: 2001. Coordenação: GRECO; Simara Maria de Souza Silveira. Curitiba: IBQP, 2001.

GEM - Global Entrepreneurship Monitor. Empreendedorismo no Brasil: 2008. Coordenação: GRECO; Simara Maria de Souza Silveira. Curitiba: IBQP, 2008.

GEM - Global Entrepreneurship Monitor. Empreendedorismo no Brasil: 2013. Coordenação: GRECO; Simara Maria de Souza Silveira. Curitiba: IBQP, 2013.

GEM - Global Entrepreneurship Monitor. Empreendedorismo no Brasil: 2014. Coordenação: GRECO; Simara Maria de Souza Silveira. Curitiba: IBQP, 2014.

GEM - Global Entrepreneurship Monitor. 2015/16 Global report. GERA, 2016.

THE GLOBAL INNOVATION INDEX. Effective Innovation Policies for Development. Fontainebleau, Ithaca, and Geneva: Cornell University, INSEAD, and WIPO, 2015.

GOMEZ-HARO, S.; ARAGÓN-CORREA, J. A.; CORDÓN-POZO, E. Differentiating the effects of the institutional environment on corporate entrepreneurship, Management Decision, v.49, n.9-10, p. 1677-1693, 2011.

HAAR, J. M.; WHITE, B. J . Corporate entrepreneurship and information technology towards employee retention: a study of New Zealand firms. Human Resourse Management Journal, v. 23, n.1, p. 109-125, 2013.

HADJIMANOLIS, A. The barriers approach to innovation. In: SHAVININA, L.V. (Org.). The International Handbook on Innovation. Oxford: Elsevier Science, 2003.p. 559-573.

HOFSTEDE, G. Culture's Consequences: Comparing Values, Behaviors, Institutions and Organizations across Nations. 2nd ed. Thousand Oaks, CA: SAGE, 2001. 
HORNSBY, J. S.; NAFFZIGER, D. W.; KURATKO, D. F.; MONTAGNO, R. V. An interactive modelo f the corporate entrepreneurship process. Entrepreneurship: Theory and Practice, v. 17 n, 2, p. 29-37, 1993.

HÜSIG, S.; KOHN, S. Factors influencing the front end of the innovation process: a comprehensive review of selected empirical NPD and explorative FFE studies. In: International Product Development Management Conference, 10., 2003. Proceedings...Brussels, Belgium: EIASM, 2003.

JONASH, R. S.; SOMMERLATTE, T. O valor da inovação. Rio de Janeiro: Campus, 2001.

KLINE, S. J.; ROSENBERG, N. An Overview of Innovation. In: LANDAU, R.; ROSENBERG, N. (Ed.). The Positive Sum Strategy: Harnessing Technology for Economic Growth. Washington, DC: National Academy Press, 1986. p. 275305.

KOEN, P. A. et al. Providing clarity and a common language to the "fuzzy front end". Research Technology Management, v. 44, n. 2, p. 46-55, 2001.

KURKKIO, M.; FRISHAMMAR, . .; LICHTENTHALER, U. Where process development begins: a multiple case study of front end activities in process firms. Technovation, v. 31, n. 9, p. 490-504, 2011.

LEWANDOWSKA, M. S.; SZYMURA-TYC, M.; GOLEBIOWSKI, T. Innovation complementarity, cooperation partners, and new product export: Evidence from Poland. Journal of Business Research, v. 69, p. 3673-3681, 2016.

MEISSNER, D.; KOTSEMIR, M. Conceptualizing the innovation process towards the 'active innovation paradigm'trends and outlook. Journal of Innovation and Entrepreneurship, v. 5, n. 14, p. 1-18, 2016.

MORRIS, G. Material benefits rise to the surface. Highways, v. 77, n. 5, p. 36-39, 2008.

OECD - ORGANIZAÇÃO DE COOPERAÇÃO E DESENVOLVIMENTO ECONÔMICO. Oslo Manual: Guide-line for collecting and interpreting innovation data, 2005. 3. ed. European Comission: OECD. Disponível em: $<$ <ttp://www.oecd.org >. Acesso em: 10 jun. 2010.

PACAGNELLA JÚNIOR, A. C.; PORTO, G. S. Análise dos fatores de influência na propensão à inovação da indústria paulista. Revista Brasileira de Inovação, v. 11, n. 2, p. 333-364, 2012.

ROBERTS, E. B. Gestión de La Innovación Tecnológica. Madrid: Fundación Cotec para La Innovación Tecnológica, 1984.

ROSENBUSCH, N.; BRINCKMANN, J.; BAUSC, A. Is innovation always beneficial? A meta-analysis of the relationship between innovation and performance in SMEs. Journal of Business Venturing, v. 26, p. 441-457, 2011.

ROTHWELL, R. Towards the Fifth-generation innovation process international. Marketing Review, v. 11, n. 1, p. 7-31, 1994.

SARQUIS et al., Processo de inovação, Fatores de influência e métricas de desempenho: proposta de modelo conceitual para empresa de base tecnológica. In: SIMPÓSIO INTERNACIONAL DE GESTÃO DE PROJ ETOS, INOVAÇÃO E SUSTENTABILIDADE, 4., 2015. São Paulo. Anais.... São Paulo: FGV/EASP, 2015. p.1-16.

SPITZECK, H.; BOECHAT, C.; LEÃO, S. F. Sustainability as a drive for innovation: towards a modelo $f$ corporate social entrepreneurship at Odebrecht in Brazil. Corporate Governance, v. 13, n. 5, p. 613-625, 2013.

TEECE, D. J . Dynamic capabilities and entrepreneurial management in large organizations: Toward a teory of the (entrepreneurial) firm. European Economic Review, v. 86, p. 202-216, jul. 2016.

TROTT, P. Gestão da Inovação e desenvolvimento de novos produtos. Porto Alegre: Bookman, 2012. 
TURRÓ, A.; URBANO, D.; PERIS-ORTIZ, M. Culture and innovation: The moderating effect of cultural values on corporate entrepreneurship. Technological Forecasting \& Social Change, v. 88, p.360-369, out. 2014.

ZAHRA, S.A. Environment, corporate entrepreneurship, and financial performance: a taxonomic approach, Journal of Business Venturing, v. 8, n.4, p. 319-340, 1993.

ANEXO A- LISTAGEM DOS PAÍSES PARTICIPANTES DA PESQUISA GEM.

\begin{tabular}{|c|c|c|c|c|c|c|c|c|c|c|c|c|c|c|c|c|}
\hline \multirow[t]{2}{*}{ Países Participantes } & \multicolumn{16}{|c|}{ Ano da Pesquisa GEM } \\
\hline & 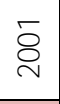 & ర్ & $\stackrel{m}{\text { ֻे }}$ & ষ্ণ & 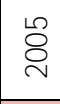 & $\mathbb{N}^{\circ}$ & ò & 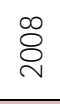 & \&্ণ & 옴 & ت્م & กิ & $\stackrel{m}{\text { กิ }}$ & ت্ণ & $\stackrel{n}{\stackrel{n}{*}}$ & total de anos \\
\hline África do Sul & & & & & & & & & & & & & & & & 14 \\
\hline Alemanha & & & & & & & & & & & & & & & & 14 \\
\hline Angola & & & & & & & & & & & & & & & & 5 \\
\hline Arábia Saudita & & & & & & & & & & & & & & & & 2 \\
\hline Argélia & & & & & & & & & & & & & & & & 4 \\
\hline Argentina & & & & & & & & & & & & & & & & 15 \\
\hline Austrália & & & & & & & & & & & & & & & & 10 \\
\hline Áustria & & & & & & & & & & & & & & & & 4 \\
\hline Bangladesh & & & & & & & & & & & & & & & & 1 \\
\hline Barbados & & & & & & & & & & & & & & & & 4 \\
\hline Bélgica & & & & & & & & & & & & & & & & 15 \\
\hline Belize & & & & & & & & & & & & & & & & 1 \\
\hline Bolívia & & & & & & & & & & & & & & & & 3 \\
\hline $\begin{array}{l}\text { Bósnia e } \\
\text { Herzegovina }\end{array}$ & & & & & & & & & & & & & & & & 7 \\
\hline Botsuana & & & & & & & & & & & & & & & & 4 \\
\hline Brasil & & & & & & & & & & & & & & & & 15 \\
\hline Bulgária & & & & & & & & & & & & & & & & 1 \\
\hline Burkina Faso & & & & & & & & & & & & & & & & 2 \\
\hline Camarões & & & & & & & & & & & & & & & & 2 \\
\hline Canadá & & & & & & & & & & & & & & & & 9 \\
\hline Catar & & & & & & & & & & & & & & & & 1 \\
\hline Cazaquistão & & & & & & & & & & & & & & & & 3 \\
\hline Chile & & & & & & & & & & & & & & & & 13 \\
\hline China & & & & & & & & & & & & & & & & 12 \\
\hline Cingapura & & & & & & & & & & & & & & & & 9 \\
\hline $\begin{array}{l}\text { Cisjordânia e Faixa } \\
\text { de Gaza }\end{array}$ & & & & & & & & & & & & & & & & 2 \\
\hline Colômbia & & & & & & & & & & & & & & & & 10 \\
\hline Coréia do Sul & & & & & & & & & & & & & & & & 9 \\
\hline Costa Rica & & & & & & & & & & & & & & & & 3 \\
\hline Croácia & & & & & & & & & & & & & & & & 14 \\
\hline Dinamarca & & & & & & & & & & & & & & & & 13 \\
\hline Egito & & & & & & & & & & & & & & & & 3 \\
\hline
\end{tabular}




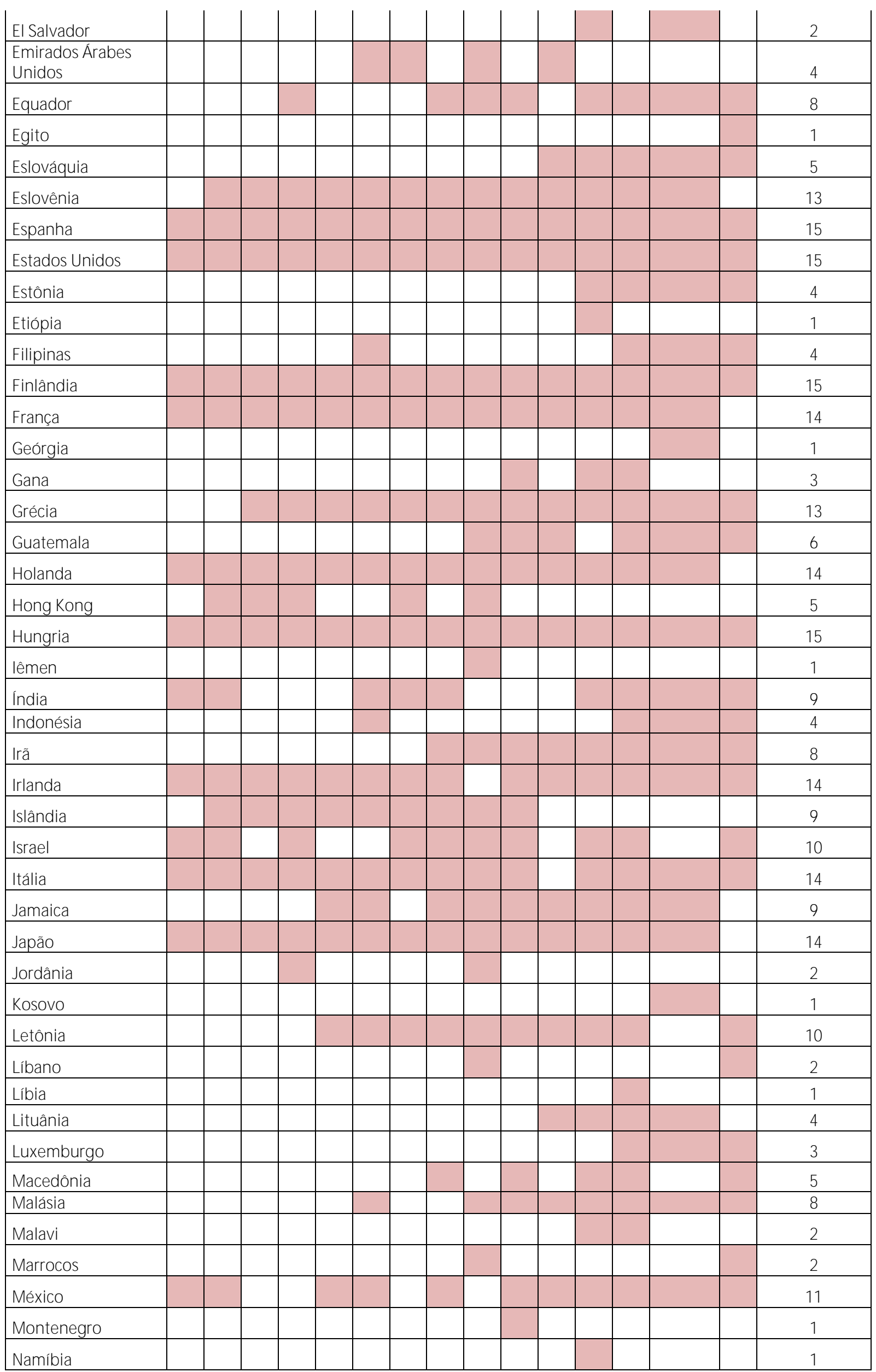




\begin{tabular}{|c|c|c|c|c|c|c|c|c|c|c|c|c|c|c|c|c|}
\hline Nigéria & & & & & & & & & & & & & & & & 3 \\
\hline Noruega & & & & & & & & & & & & & & & & 15 \\
\hline Nova Zelândia & & & & & & & & & & & & & & & & 5 \\
\hline Países Baixos & & & & & & & & & & & & & & & & 1 \\
\hline Palestina & & & & & & & & & & & & & & & & 1 \\
\hline Panamá & & & & & & & & & & & & & & & & 6 \\
\hline Paquistão & & & & & & & & & & & & & & & & 4 \\
\hline Peru & & & & & & & & & & & & & & & & 11 \\
\hline Polônia & & & & & & & & & & & & & & & & 8 \\
\hline Porto Rico & & & & & & & & & & & & & & & & 4 \\
\hline Portugal & & & & & & & & & & & & & & & & 8 \\
\hline Reino Unido & & & & & & & & & & & & & & & & 15 \\
\hline $\begin{array}{l}\text { República } \\
\text { Dominicana }\end{array}$ & & & & & & & & & & & & & & & & 4 \\
\hline República Tcheca & & & & & & & & & & & & & & & & 3 \\
\hline Romênia & & & & & & & & & & & & & & & & 9 \\
\hline Rússia & & & & & & & & & & & & & & & & 11 \\
\hline Senegal & & & & & & & & & & & & & & & & 1 \\
\hline Sérvia & & & & & & & & & & & & & & & & 3 \\
\hline Singapura & & & & & & & & & & & & & & & & 1 \\
\hline Síria & & & & & & & & & & & & & & & & 1 \\
\hline Suécia & & & & & & & & & & & & & & & & 13 \\
\hline Suíça & & & & & & & & & & & & & & & & 11 \\
\hline Suriname & & & & & & & & & & & & & & & & 2 \\
\hline Tailândia & & & & & & & & & & & & & & & & 9 \\
\hline Taiwan & & & & & & & & & & & & & & & & 6 \\
\hline Tonga & & & & & & & & & & & & & & & & 1 \\
\hline Trinidad e Tobago & & & & & & & & & & & & & & & & 5 \\
\hline Tunísia & & & & & & & & & & & & & & & & 4 \\
\hline Turquia & & & & & & & & & & & & & & & & 6 \\
\hline Uganda & & & & & & & & & & & & & & & & 7 \\
\hline Uruguai & & & & & & & & & & & & & & & & 10 \\
\hline Vanuatu & & & & & & & & & & & & & & & & 1 \\
\hline Venezuela & & & & & & & & & & & & & & & & 5 \\
\hline Vietnam & & & & & & & & & & & & & & & & 3 \\
\hline Zâmbia & & & & & & & & & & & & & & & & 3 \\
\hline $\begin{array}{l}\text { países } \\
\text { participantes/ano }\end{array}$ & 28 & 37 & 32 & 34 & 35 & 42 & 42 & 43 & 56 & 60 & 54 & 69 & 67 & 70 & 59 & \\
\hline
\end{tabular}




\section{ANEXO B - CLASSIFICAÇÃO ECONÔMICA DOS PAÍSES É A UTILIZADA NA PESQUISA GEM ADAPTADA DA COMPOSIÇÃO DE MACRORREGIÕES GEOGRÁFICAS DO MUNDO USADA PELAS NAÇÕES UNIDAS.}

\begin{tabular}{|c|c|c|c|}
\hline Economia impulsionada por: & Fatores & Eficiência & Inovação \\
\hline \multirow[t]{14}{*}{ África } & Botswana & África do Sul & \\
\hline & Camarão & \multirow[t]{13}{*}{ Marrocos } & \\
\hline & Egito & & \\
\hline & Senegal & & \\
\hline & Tunísia & & \\
\hline & Burkina Faso & & \\
\hline & Argélia & & \\
\hline & Gana & & \\
\hline & Angola & & \\
\hline & Líbia & & \\
\hline & Malavi & & \\
\hline & Nigéria & & \\
\hline & Uganda & & \\
\hline & Zâmbia & & \\
\hline \multirow[t]{7}{*}{ Ásia e Oceania } & Índia & China & Austrália \\
\hline & Filipinas & Indonésia & Israel \\
\hline & Irã & Cazaquistão & Japão \\
\hline & \multirow[t]{4}{*}{ Vietnam } & Líbano & Coreia do Sul \\
\hline & & Malásia & Taiwan \\
\hline & & Tailândia & \multirow[t]{2}{*}{ Singapura } \\
\hline & & Rússia & \\
\hline \multirow[t]{14}{*}{ América Latina e Caribe } & & Argentina & \multirow[t]{14}{*}{ Trinidad e Tobago } \\
\hline & & Barbados & \\
\hline & & Brasil & \\
\hline & & Chile & \\
\hline & & Colômbia & \\
\hline & & Equador & \\
\hline & & Guatemala & \\
\hline & & México & \\
\hline & & Panamá & \\
\hline & & Peru & \\
\hline & & Porto Rico & \\
\hline & & Uruguai & \\
\hline & & Suriname & \\
\hline & & Jamaica & \\
\hline \multirow[t]{12}{*}{ Europa } & & Bulgária & Bélgica \\
\hline & & Croácia & Finlândia \\
\hline & & Estônia & Alemanha \\
\hline & & Hungria & Grécia \\
\hline & & Letônia & Irlanda \\
\hline & & Polônia & Itália \\
\hline & & Romênia & Luxemburgo \\
\hline & & Macedônia & Holanda \\
\hline & & Bósnia & Noruega \\
\hline & & Lituânia & Portugal \\
\hline & & & Eslovênia \\
\hline & & & Eslováquia \\
\hline
\end{tabular}




\begin{tabular}{|l|l|l|} 
& & Espanha \\
& & Suécia \\
\hline & & Suíça \\
\hline & & Reino Unido \\
\hline & & França \\
\hline América do Norte & República Tcheca \\
\hline & & Canadá \\
\hline & & Estados Unidos \\
\hline & & Porto Rico \\
\hline
\end{tabular}

Fonte: GEM, 2016.

\section{ANEXO C - TABELA COM VALORES DAS VARIÁVEIS DE 2001 A 2015.}

\begin{tabular}{|c|c|c|c|c|c|c|c|c|}
\hline Variável & 2001 & 2002 & 2003 & 2004 & 2005 & 2006 & 2007 & 2008 \\
\hline $\begin{array}{l}\text { Oportunidades percebidas } \\
\text { (\% da população de } 18 \text { a } 64 \text { anos } \\
\text { que vê boas oportunidades para } \\
\text { iniciar uma empresa na área onde } \\
\text { vivem) }\end{array}$ & 41 & 41 & 41 & 44 & 43 & 37 & 39 & 41 \\
\hline $\begin{array}{l}\text { Capacidades percebidas pelo } \\
\text { empreendedor } \\
\text { (\% da população de } 18 \text { a } 64 \text { anos } \\
\text { que acreditam ter habilidades e } \\
\text { conhecimento necessários para } \\
\text { iniciar um negócio) }\end{array}$ & 54 & 55 & 51 & 56 & 50 & 54 & 54 & 53 \\
\hline $\begin{array}{l}\text { Atividade empresarial de um } \\
\text { novo produto } \\
\text { (\% da população de } 18 \text { a } 64 \text { anos } \\
\text { que conhecem novos produtos que } \\
\text { obtiveram sucesso) }\end{array}$ & & 24,59 & 17,55 & 15,66 & 15,83 & 23,48 & 20,74 & 16,34 \\
\hline $\begin{array}{l}\text { Atividade empreendedora como } \\
\text { Oportunidade de melhoria } \\
\text { (\% das pessoas envolvidas no TEA } \\
\text { que (i) afirmam ser conduzidas pela } \\
\text { oportunidade ao invés de não } \\
\text { encontrar nenhuma outra opção para } \\
\text { o trabalho; e (ii) quem indica o } \\
\text { principal motor de envolvimento } \\
\text { nesta oportunidade é ser }\end{array}$ & 38 & 38 & 38 & 38 & 38 & 40 & 38 & 46 \\
\hline $\begin{array}{l}\text { TEA (empreendedores } \\
\text { nascentes) }\end{array}$ & 13,8 & 13,53 & 12,90 & 13,48 & 11,32 & 11,65 & 12,72 & 12,02 \\
\hline $\begin{array}{l}\text { TEA (proprietários de um } \\
\text { negócio estabelecido) }\end{array}$ & 3,79 & 7,76 & 7,62 & 10,11 & 10,11 & 12,09 & 9,94 & 14,59 \\
\hline $\begin{array}{l}\text { TEA empreendedor por } \\
\text { necessidade }\end{array}$ & 37,43 & 55,02 & 42,66 & 46,12 & 47,11 & 47,66 & 41,6 & 32,87 \\
\hline TEA por oportunidade & & & & & 37,86 & 40 & 38,07 & 45,56 \\
\hline
\end{tabular}

Continua... 


\begin{tabular}{|c|c|c|c|c|c|c|c|}
\hline Variável & 2009 & 2010 & 2011 & 2012 & 2013 & 2014 & 2015 \\
\hline $\begin{array}{l}\text { Oportunidades percebidas } \\
\text { (\% da população de } 18 \text { a } 64 \text { anos que vê } \\
\text { boas oportunidades para iniciar uma } \\
\text { empresa na área onde vivem) }\end{array}$ & 47 & 48 & 43 & 52 & 50,93 & 55,54 & 42,4 \\
\hline $\begin{array}{l}\text { Capacidades percebidas pelo } \\
\text { empreendedor } \\
\text { (\% da população de } 18 \text { a } 64 \text { anos que } \\
\text { acreditam ter habilidades e conhecimento } \\
\text { necessários para iniciar um negócio) }\end{array}$ & 53 & 58 & 53 & 54 & 52,62 & 50 & 58,3 \\
\hline $\begin{array}{l}\text { Atividade empresarial de um novo } \\
\text { produto } \\
\text { (\% da população de } 18 \text { a } 64 \text { anos que } \\
\text { conhecem novos produtos que obtiveram } \\
\text { sucesso) }\end{array}$ & 22,45 & 16,77 & 11,46 & 11,31 & 11,21 & 21,88 & 28,39 \\
\hline $\begin{array}{l}\text { Atividade empreendedora como } \\
\text { Oportunidade de melhoria } \\
\text { (\% das pessoas envolvidas no TEA que (i) } \\
\text { afirmam ser conduzidas pela oportunidade } \\
\text { ao invés de não encontrar nenhuma outra } \\
\text { opção para o trabalho; e (ii) quem indica o } \\
\text { principal motor de envolvimento nesta } \\
\text { oportunidade é ser independente ou } \\
\text { aumentar sua renda, em vez de apenas }\end{array}$ & 48 & 46 & 45 & 59 & 57,36 & 57,81 & 47,79 \\
\hline TEA (empreendedores nascentes) & 15,32 & 17,50 & 14,89 & 15,44 & 17,31 & 17,23 & 20,98 \\
\hline $\begin{array}{l}\text { TEA (proprietários de um negócio } \\
\text { estabelecido) }\end{array}$ & 11,84 & 15,26 & 12,23 & 15,19 & 15,44 & 17,51 & 18,89 \\
\hline TEA empreendedor por necessidade & 38,7 & 31,06 & 30,66 & 30,13 & 28,60 & 28,95 & 42,87 \\
\hline TEA por oportunidade & 47,66 & 45,91 & 45,16 & 58,83 & 57,36 & 57,81 & 47,79 \\
\hline
\end{tabular}

Fonte: GEM, 2016. 